\title{
ORA ESTÁ, ORA NÃO ESTÁ: INPUT VARIÁVEL E AQUISIÇÃO DA FLEXÃO VERBAL DE 3a PESSOA DO PLURAL NO PB ${ }^{1}$
}

\author{
Daniele Molina \\ (NEALP/UFJF) \\ Mercedes Marcilese \\ (NEALP/UFJF) \\ Cristina Name \\ (NEALP/UFJF/CNPq)
}

\section{RESUMO}

Este artigo investiga a percepção do morfema flexional de $3^{\mathrm{a}}$ pessoa do plural em verbos e a compreensão da informação de pluralidade veiculada por tal morfema por crianças adquirindo o $\mathrm{PB}$, tendo em vista que a realização da flexão de número mostra-se variável nessa língua, tanto no âmbito nominal quanto verbal. Estudos prévios em diferentes línguas sugerem que, embora essa flexão seja produzida por volta dos três anos de idade, até os seis anos, crianças apresentam dificuldades na sua interpretação em tarefas de compreensão (JOHNSON; DE VILLIERS; SEYMOR, 2005; PÉREZ-LEROUX, 2005; LEGENDRE et al., 2010; BLÁHOVÁ; SMOLIK, 2014). Na presente pesquisa, foi conduzido um estudo experimental, por meio de uma tarefa de seleção de imagens, buscando verificar se, (i) apesar do caráter variável da marcação de número no $\mathrm{PB}$, crianças aos seis e aos cinco anos de idade identificam a forma verbal de $3^{\text {a }}$ pessoa do plural em sentenças com sujeito nulo (Comeram doce); (ii) associam essa forma a uma ação praticada por mais de uma entidade e (iii) se a forma verbal no singular é associada ao conceito de singularidade (Cотеи doce). Enunciados contendo a informação redundante de número no sujeito e no verbo também foram testados (As crianças comeram doce vs. A criança comeu doce). Os resultados apontam para uma sistematicidade na escolha pela imagem congruente com os estímulos linguísticos no plural, apesar da preferência pela imagem plural também nas sentenças no singular. A variabilidade identificada no input parece não interferir na percepção e na compreensão do morfema verbal de plural na faixa etária avaliada. 
PALAVRAS-CHAVE: aquisição verbal; variação linguística; flexão verbal variável; percepção; compreensão.

\section{Introdução}

A maior parte dos estudos sobre aquisição da linguagem investiga a aquisição de propriedades invariantes da língua. São poucos os estudos que tomam como objeto de pesquisa a aquisição de propriedades linguísticas variáveis, apesar da relevante relação entre aquisição da linguagem, variação e mudança linguística (LIGHTFOOT, 2010).

Estudos da aquisição da linguagem no âmbito da Psicolinguística partem, muitas vezes, da perspectiva do processamento da informação e assumem que o que é gramaticalmente relevante para a aquisição mostra-se regular e frequente no input da língua a ser adquirida. Tais estudos apontam ainda para habilidades precoces de percepção de padrões fônicos e distribucionais dos chamados itens funcionais, tais como determinantes, flexão, tempo etc., que seriam essenciais como alavancagem para a aquisição (ver CORRÊA, NAME e FERRARI-NETO, 2004).

A aquisição verbal, em particular, ocorreria, a partir dessa perspectiva, por meio da identificação de afixos verbais regulares na língua e de pistas distribucionais frequentes no input. $\mathrm{O}$ reconhecimento de afixos de tempo e modo, por exemplo, permitiria à criança, em fase inicial de aquisição, identificar, em uma forma verbal, as propriedades flexionais do verbo e a tomar a raiz verbal como parte que contém um significado permanente que pode ser combinada a diversas flexões gramaticais, dependendo da intenção de fala e do contexto sintático (MOLINA, 2014; NAME; MOLINA, 2014).

No entanto, a identificação da informação de número associada à flexão dos verbos parece apresentar dificuldades para a criança, pelo menos no que diz respeito a tarefas experimentais de compreensão. Estudos desenvolvidos em diversas línguas, com sistemas diversos de marcação flexional em verbos, apontam para dificuldades na interpretação da informação de número, sugerindo que seria custosa a consolidação do mapeamento entre os morfemas de número e a informação conceitual relativa à numerosidade associada a esses elementos (singular, plural ou dual, dependendo da língua em questão), mesmo em línguas em que os paradigmas flexionais de número apresentam-se consistentes. Tais estudos, desenvolvidos em inglês, espanhol, francês e eslavo, sugerem que as crianças apresentam dificuldades em tarefas de compreensão dos morfe- 
mas de número em verbos, embora não apresentem dificuldades na produção linguística desses mesmos morfemas (JOHNSON; DE VILLIERS; SEYMOR, 2005; PÉREZ-LEROUX, 2005; LEGENDRE et al., 2010; BLÁHOVÁ; SMOLIK, 2014). Os resultados desses estudos, conduzidos com crianças entre três e seis anos de idade, apontam para melhores desempenhos por volta dos cinco e dos seis anos, com uma melhora gradual na realização da tarefa se comparados grupos de participantes das quatro faixas etárias (três, quatro, cinco e seis anos de idade). As dificuldades de compreensão reportadas poderiam estar relacionadas a aspectos da computação sintática de relações de concordância, que demandariam habilidades assimétricas na produção e na compreensão de morfemas verbais, a limitações pragmáticas na execução das tarefas de compreensão em tais estudos e/ou a dificuldades no desenvolvimento do conhecimento conceitual de número. No caso das línguas que apresentam propriedades variáveis no input, pode-se pensar que haveria uma dificuldade adicional para a percepção do morfema de número, uma vez que a criança teria que lidar com a alternância de elementos ou com a variabilidade entre presença e ausência da marcação morfofonológica, como parece ser o caso do português brasileiro (doravante $\mathrm{PB}$ ).

De acordo com Miller e Schmitt (2009; 2012), propriedades que apresentam variação de caráter intra ou extralinguístico podem impactar a produção e a compreensão da morfologia de número, adicionando dificuldade à aquisição morfológica, causada pela ambiguidade apresentada no material linguístico disponível para a criança. As autoras, ao compararem os resultados de compreensão de morfemas de número por crianças adquirindo o espanhol chileno, que apresenta variação entre produção e omissão da marcação de plural /-s/, e o espanhol mexicano, em que a produção do plural é categórica, assumem a Hipótese de Atraso pela Variabilidade (Variability Delay Hypothesis), originalmente proposta por Yang (2002). Segundo tal hipótese, um input variável provocaria um atraso na compreensão do morfema gramatical de número se comparado à aquisição de uma língua em que o input apresenta-se de forma consistente.

Assim como o espanhol chileno, o PB apresenta variação na marcação de número, tanto no domínio da concordância nominal (ex.: Essas meninas vs. Essas meninaø), quanto nas relações de concordância entre sujeito e verbo (ex.: Elas usam óculos vs. Elas usaø óculos) ${ }^{2}$. Dessa forma, o PB apresenta duas regras gerais de marcação de número: uma em que a marcação morfofonológica apresenta-se de maneira redundante 
em todos os elementos passíveis de serem flexionados; e outra em que a marcação não é redundante, ou seja, em que o plural é marcado, em geral, apenas no determinante.

Conforme documentado pela Sociolinguística Variacionista, a variação na flexão de número no PB parece estar bastante disseminada na língua, sendo a variação entre marcação redundante e não redundante influenciada por fatores linguísticos e extralinguísticos. O que se percebe é que a variação, antes atribuída à baixa escolarização de falantes menos favorecidos socioeconomicamente, passa a englobar a fala de brasileiros de todos os níveis socioeconômicos, apresentando caráter variável na fala de um mesmo indivíduo. A marcação variável de plural deve ser levada em consideração, portanto, nos estudos sobre a aquisição da morfofonologia do $\mathrm{PB}$, já que é uma característica da produção linguística dos falantes adultos, estando, consequentemente, presente no input linguístico com o qual a criança em fase de aquisição da língua está em contato.

A variação presente no input ganhou destaque na literatura em estudos que abordam a aquisição/aprendizagem de L2, ao passo que ainda são escassos os trabalhos que investigam o processo de aquisição de língua materna a partir de um input variável. No que tange à marcação morfofonológica de número em verbos, muitas pesquisas são desenvolvidas com crianças a partir de estudos longitudinais, ou seja, por meio exclusivamente da coleta de dados de fala de produção espontânea (FIGUEIRA, 2003; LOPES; SOUZA; ZILLI, 2005; GOMES et al., 2011), havendo ainda uma significativa lacuna de pesquisas com foco na compreensão de morfemas verbais de número.

No que diz respeito à compreensão da marcação morfofonológica de número, Ferrari-Neto $(2003,2008)$ aponta para a compreensão da marcação morfofonológica de plural no DP (Determiner Phrase - sintagma determinante) por crianças adquirindo o PB com média de idade de dois anos, inclusive quando os estímulos são apresentados na variedade não redundante (com marcação explícita de plural em $\mathrm{D}$, mas não no nome (N) - ex.: os daboø). Além disso, as crianças não apresentaram dificuldades de compreensão em tarefas realizadas a partir de estímulos linguísticos que consideravam alomorfes de plural (/-s/ e /-es/). Mesmo quando comparados participantes provenientes de dois grupos socioeconômicos distintos, não houve diferenças estatisticamente significativas no desempenho das crianças.

A presente pesquisa busca contribuir para os estudos acerca da 
aquisição da linguagem a partir de um input variável, investigando a compreensão de sentenças por crianças nas faixas dos 5 e 6 anos de idade. Para tal, contrastamos a compreensão de sentenças com marcação morfofonológica redundante no sujeito e no verbo com sentenças nas quais a única informação de número disponível apresenta-se no verbo (i.e. sentenças de sujeito nulo).

O artigo está organizado da seguinte forma: discorremos, inicialmente, sobre a Teoria de Princípios e Parâmetros, com vistas a discutir os conceitos de gramática nuclear e periferia marcada (CHOMSKY, 1981; KATO, 2005), que são utilizados para embasar nossa proposta de discussão relativa à aquisição da morfologia verbal de número no $\mathrm{PB}$, e sobre a literatura disponível sobre a aquisição de propriedades que se apresentam variáveis no input. Recorremos à literatura da Sociolinguística Variacionista e a dados de produção espontânea (MOLINA, em prep.) para caracterizar, de forma sucinta, a produção de falantes adultos do PB, principais interlocutores das crianças em fase de aquisição da língua. $\mathrm{Na}$ sequência, passamos à apresentação da tarefa de compreensão por nós desenvolvida, à análise e à discussão dos dados e dos resultados encontrados. Por fim, tecemos as conclusões a que, por ora, nossos resultados nos permitem chegar.

\section{A aquisição da linguagem a partir de um input variável}

Aspectos linguísticos variáveis dentro de uma mesma língua podem ser tomados como potenciais indícios de mudança linguística em progresso. Nesse sentido, destaca-se a importância dos estudos acerca da variação linguística, uma vez que se entende que formas variantes tendem a se mostrar instáveis na língua, podendo uma forma se sobrepor à outra ao longo do tempo.

Assumindo-se a aquisição da linguagem a partir da Teoria de Princípios e Parâmetros, tem-se que Chomsky $(1981$; 1986) distingue os conceitos de Língua-I e Língua-E. A Língua-I é tomada como a língua interna, intensional e individual, ao passo que a Língua-E é entendida como externa e extensional. Ao assumir como objeto de estudo a Língua-I, a teoria gerativa compreende que a língua internalizada, que permite ao falante produzir e compreender sentenças, é composta por dois tipos de propriedades: a) propriedades invariantes que definem as línguas naturais 
- os princípios; e b) propriedades variáveis que podem ser marcadas pelos valores positivo (+) e negativo (-) de acordo com o input ao qual a criança é exposta - os parâmetros.

Segundo tal teoria, quando todos os valores dos parâmetros encontram-se fixados, temos uma gramática nuclear, ou seja, naturalmente internalizada. Como discutido por Kato (2005), uma gramática nuclear pode subjazer a muitas Línguas-I, já que o conhecimento linguístico não é exatamente igual para todos os falantes de uma mesma comunidade. Em oposição à gramática nuclear, a Língua-I também seria composta por uma gramática periférica, também chamada de periferia marcada, a qual abrigaria fenômenos relativos a empréstimos, resíduos de mudança, invenções, regras linguísticas aprendidas por meio do processo de escolarização etc., que poderiam aparecer de forma marginal na fala do indivíduo.

Determinados processos de mudança podem ser interpretados como resultado de uma alteração em um ou mais parâmetros da língua. Para Avelar (2006), do ponto de vista do processo de aquisição, a variação não deve ser tomada como indício de uma mudança em progresso, mas como uma mudança ocorrida no processo de aquisição da linguagem de uma geração da comunidade de fala que fixa um ou mais parâmetros da língua diferentemente da marcação apresentada pela gramática da geração precedente.

Lessa-de-Oliveira (2005), ao tratar da aquisição de estruturas-QU no $\mathrm{PB}$, destaca que a variação dialetal encontrada na língua interfere no processo de aquisição. Ao comparar a aquisição de interrogativas-QU por crianças expostas a dialetos distintos, a autora argumenta que o processo não segue obrigatoriamente o mesmo itinerário, sugerindo que a frequência dos tipos de interrogativas-QU no input e a ordem em que essas estruturas aparecem no material linguístico disponível seriam pontos relevantes.

A variação presente no input também se mostra importante na comparação feita por Castro e Ferrari-Neto (2007) entre crianças adquirindo o PB e o PE (português europeu) no que tange à concordância no DP. Os autores destacam que, enquanto as crianças brasileiras tratam DPs com marcação não redundante (ex.: os daboø) e DPs com marcação redundante (ex.: os dabos) de forma semelhante, inclusive registrando mais respostas plurais para a condição não redundante, as crianças portuguesas reconhecem os daboø como plural, embora de maneira diferente da percepção de os dabos. As crianças portuguesas parecem identificar mais facilmente a noção de pluralidade na condição redundante, ao contrário 
do que acontece com as brasileiras, sugerindo que a exposição a estímulos linguísticos diferentes, no que se refere à sistematicidade da marcação morfofonológica de número (o PE teria, portanto, um sistema de marcação de número mais categórico do que o PB), parece afetar o modo como as crianças tratam a informação morfofonológica relativa a número no âmbito do DP.

Nosso trabalho busca discutir o papel da variabilidade entre presença e ausência da marcação de plural na compreensão do morfema verbal de número no $\mathrm{PB}$, uma vez que as teorias de aquisição em geral sustentam, como mencionado anteriormente, que o que é gramaticalmente relevante na aquisição da língua mostra-se de maneira sistemática e frequente no input. Passamos, portanto, a uma caracterização sincrônica da flexão de $3^{\mathrm{a}}$ pessoa do plural nessa língua, com vistas a descrever o input recebido pelas crianças em fase de aquisição do PB.

\section{A flexão de $3^{\text {a }}$ pessoa do plural no input de crian- ças adquirindo o PB}

Em relação ao caráter variável da flexão de $3^{\mathrm{a}}$ pessoa do plural em verbos no PB, Duarte (1996) aponta para a redução dos paradigmas verbais que passaram, inicialmente, de seis formas distintivas para quatro, com a perda do traço distintivo de $2^{\mathrm{a}}$ pessoa, chegando, atualmente, a três formas distintivas, se considerada a inserção da expressão "a gente" no lugar do pronome pessoal "nós", e a apenas duas formas em algumas variedades que contrastam a $1^{\text {a }}$ pessoa do singular de todas as outras pessoas do discurso.

Para Galves (1996), a ausência da $2^{\mathrm{a}}$ pessoa tornaria a concordância, no PB, fraca morfologicamente, ao passo que a indeterminação da $3^{\mathrm{a}}$ pessoa tornaria a concordância fraca semanticamente, o que demandaria o preenchimento fonológico da posição do sujeito. Em casos de sujeito nulo, a interpretação semântica seria feita a partir do contexto discursivo disponível.

Em uma análise comparativa entre a concordância no PE (marcada em todos os elementos passíveis de flexionar em número) e no PB (que apresenta concordância variável), Costa e Figueiredo Silva (2002) defendem que a distinção na realização da concordância verbal nas duas variedades do português não estaria no movimento sintático do verbo (de $\mathrm{V}$ para $\mathrm{T}$ - i.e., do núcleo do sintagma verbal para o núcleo funcional relativo à flexão verbal), mas no tipo de morfema flexional associado ao 
verbo. Os autores postulam que, no $\mathrm{PB}$, o morfema de número é do tipo singleton, isto é, só se manifesta em um único núcleo, enquanto que, no $\mathrm{PE}$, trata-se de um morfema dissociado (dissociated morpheme), sendo inserido pós-sintaticamente em todos os itens passíveis de receber marcação de plural.

Estudos de cunho sociolinguístico buscam descrever, a partir da análise sincrônica e diacrônica de dados de fala, a variação e a mudança linguísticas inerentes às línguas naturais. Muitas pesquisas no âmbito da literatura sociolinguística destacam a natureza variável da concordância de número no PB, tanto no domínio nominal quanto na relação entre sujeito e verbo. A variação entre marcação morfofonológica redundante e não redundante seria, de acordo com essas pesquisas, influenciada por fatores linguísticos e extralinguísticos. Alguns dos principais fatores linguísticos apontados são o grau de saliência fônica na comparação das formas de singular e de plural de um mesmo item, a posição do sujeito em relação ao verbo (anteposto/posposto), a distância entre sujeito e verbo, o traço de animacidade associado ao sujeito e o paralelismo linguístico e oracional (LEMLE; NARO, 1977; NARO, 1981; NARO; SCHERRE, 2007).

Quanto às variáveis extralinguísticas, o fator anos de escolarização é apontado como relevante, sendo que os falantes com maior grau de escolarização tendem a aplicar as regras de marcação redundante de forma mais sistemática do que os falantes com menos anos de escolarização. Além disso, as mulheres parecem utilizar com maior frequência a concordância redundante do que os homens, bem como as pessoas em idade de inserção no mercado de trabalho (SCHERRE; NARO, 1998; 2006).

Com o intuito de verificar a ocorrência da flexão verbal variável no input recebido por crianças em processo de aquisição da linguagem e na própria produção infantil, Molina (em prep.) analisou a fala espontânea de quatro crianças e de seus cuidadores (principalmente mães com alto nível de escolarização) em contextos de interação. Um dos objetivos desse estudo é investigar o quão variável é a marcação de plural em verbos de $3^{\text {a }}$ pessoa no input que a criança recebe e averiguar se a produção linguística da criança apresenta caráter variável, semelhante (ou não) ao encontrado na fala do adulto. A análise preliminar dos dados aponta para uma predominância de sentenças com marcação morfofonológica explícita de plural em verbos em contextos de $3^{\text {a }}$ pessoa na fala dos adultos: $89 \%$ dos enunciados apresentaram marcação redundante e $11 \%$ apresentaram marcação não redundante. Já na fala das crianças, constatou-se maior variação entre 
marcação redundante e não redundante do que na fala dos adultos: $66 \%$ dos enunciados apresentaram marcação morfofonológica de plural no verbo, ao passo que 34\% apresentaram marcação não redundante.

$\mathrm{O}$ estudo longitudinal ainda em andamento instiga-nos a investigar se a variação atestada na marcação morfofonológica já faria parte da gramática nuclear das crianças, ou seja, se a possibilidade de alternância na marcação de plural no verbo seria adquirida naturalmente. Nesse sentido, pode-se pensar que a marcação redundante, como regra categórica, segundo o defendido por Kato (2005), faria parte da periferia marcada, na qual valores distintos dos encontrados na gramática nuclear seriam estabelecidos por meio do processo de escolarização.

Interessa-nos aqui investigar experimentalmente se a variação na marcação morfofonológica de plural no verbo - observada no input ao qual a criança está exposta - interfere no processo de compreensão de sentenças por crianças de cinco e de seis anos de idade, já que, se há variação na marcação explícita de plural em contextos semânticos equivalentes (As criança(s) gosta $(m)$ de brincar), o input que a criança recebe não seria robusto quanto às informações da morfologia verbal no PB. Passamos, assim, à descrição do estudo experimental desenvolvido.

\section{Estudo experimental sobre a compreensão do morfema verbal de $3^{\text {a }}$ pessoa no $\mathrm{PB}$}

Conduzimos uma atividade experimental que buscou verificar o mapeamento da marcação morfofonológica de número ao conceito de singular e plural por crianças de cinco e seis anos de idade. Para tal, contrastamos sentenças com sujeito foneticamente preenchido por um DP (A criança comeu doce vs. As crianças comeram doce) e com sujeito nulo (Comeu doce vs. Comeram doce), com vistas a verificar se a informação de número reforçada pela marcação morfofonológica presente no sujeito e no verbo facilita a identificação do referente ou se a marcação flexional apenas no verbo é suficientemente robusta para a interpretação semântica do enunciado. Cabe lembrar que, em virtude da natureza variável da realização da concordância no PB, a marcação de número no sujeito constituiria uma fonte de informação mais confiável para a criança em fase de aquisição da língua. A marcação morfológica de número no verbo, por sua vez, pode não ser robusta e sistemática o suficiente, já que verbos com morfologia singular podem acompanhar sujeitos plurais.

Partimos da hipótese de que, quando a informação de número plu- 
ral é reforçada pela marcação morfofonológica redundante no sujeito e no verbo, a identificação do referente é facilitada. Já no caso da realização morfofonológica no verbo como única informação de numerosidade, a identificação do referente pode ser dificultada em função da variação na expressão da concordância entre sujeito/verbo discutida anteriormente.

Além do contraste entre sentenças com sujeito preenchido e sentenças com sujeito nulo, foram testados grupos socioeconômicos distintos a fim de investigar a possível influência da frequência da marcação redundante no input ao qual a criança está exposta. De acordo com Alves, Soares e Xavier (2014), as escolas privadas agregam alunos com nível socioeconômico mais alto, ao passo que alunos de escolas municipais e estaduais seriam de níveis socioeconômicos mais baixos. Partimos, assim, do pressuposto de que as crianças provenientes de escolas privadas e, portanto, de nível socioeconômico mais alto, estariam expostas com mais frequência à realização morfofonológica redundante de número, conforme é apontado pela literatura sociolinguística.

\subsection{Método}

Design Experimental: Consideramos como variáveis independentes a realização do sujeito (nulo x preenchido); a informação de número (singular x plural); a faixa etária dos participantes (5 anos x 6 anos) e o grupo socioeconômico dos participantes (escola pública $\mathrm{x}$ escola privada). As duas primeiras variáveis foram medidas repetidas e as duas últimas fatores grupais. A variável dependente considerada foi a taxa de escolha da imagem congruente ao estímulo linguístico. Dessa forma, foram estabelecidas as seguintes condições experimentais:

Condição sujeito nulo singular (SNS): Comeu doce.

Condição sujeito nulo plural (SNP): Comeram doce.

Condição sujeito preenchido singular (SPS): A criança comeu doce. Condição sujeito preenchido plural (SPP): As crianças comeram doce.

Previsões: A condição SPP deve registrar o maior número de respostas-alvo, uma vez que a presença de marcação de número no sujeito e no verbo deixaria essa informação mais saliente do ponto de vista perceptual. Além disso, se a criança já possui capacidade de percepção e compreensão do morfema de plural, a condição SNP também deve registrar alto percentual de respostas-alvo, embora o sujeito nulo possa adicionar dificuldade à tarefa. Já as condições de singular, se comparadas às de 
plural, devem registrar números mais baixos de respostas-alvo, principalmente quando associadas ao sujeito nulo, já que verbos com morfologia de singular não necessariamente são associados à noção de singularidade na língua. Assim, a condição SPS deve registrar maior número de respostas-alvo do que na condição SNS, tendo em vista que o preenchimento do sujeito auxiliaria na interpretação. Espera-se também que as crianças de 6 anos apresentem melhor desempenho, em função de uma possível consolidação do mapeamento entre os morfemas de singular e de plural e o conceito de numerosidade em função da idade, e que o grupo socioeconômico exposto à concordância redundante com maior frequência (escola privada) apresente melhor desempenho na tarefa.

Participantes: 148 crianças monolíngues adquirindo o $\mathrm{PB}$, sendo 40 de 6 anos de idade provenientes de escola pública; 44 de 6 anos de idade provenientes de escola privada, 32 de 5 anos de idade provenientes de escola pública e 32 de 5 anos de idade provenientes de escola privada.

Materiais: $\mathrm{O}$ experimento foi conduzido por meio da técnica de seleção de imagens. Foram criadas pranchas de desenhos que mostram sempre duas personagens: em uma das imagens, as duas personagens estão praticando uma determinada ação; na outra, apenas uma das personagens está praticando essa ação. As duas imagens eram apresentadas juntamente com os estímulos linguísticos. Nesse sentido, o método utilizado foi semelhante ao empregado por Legendre et al. (2010) no francês. Diferentemente, em pesquisa conduzida em espanhol, Pérez-Leroux (2005) adotou o mesmo tipo de tarefa, mas contrastando uma imagem contendo um único referente e outra contendo dois referentes (ex.: uma imagem apresentando um único pato nadando vs. uma imagem com mais de um pato nadando). Embora em termos linguísticos o espanhol - na variedade investigada - apresente marcação verbal de número sistemática e consistente, os resultados desse estudo para frases no singular ficaram no nível da chance. Isso sugere que o fato de haver um contraste perceptualmente nítido entre ambas as imagens apresentadas não seria um fator facilitador quando os estímulos linguísticos são singulares. Assim, tomando como ponto de partida os estudos prévios em francês e espanhol, optamos por apresentar, em ambas as imagens, duas personagens, com o intuito de garantir que a escolha da criança não fosse pautada em uma preferência pela imagem com mais personagens (i.e., visualmente mais atraente) e que a necessidade de analisar as figuras de maneira mais detalhada mantivesse os participantes atentos até o final da tarefa. 
Numa versão piloto do experimento, a tarefa foi aplicada com as formas verbais das sentenças no presente do indicativo, já que o objetivo era o de contrastar a presença explícita do morfema de número (ex.: come- $m$ ) com a ausência desse morfema (ex.: come-ø), seguindo os moldes dos estudos conduzidos em outras línguas. No entanto, além de o presente simples do indicativo ser menos frequente no $\mathrm{PB}$, sendo mais usado o presente contínuo (ex.: está/estão comendo), esse tempo verbal parece favorecer uma leitura genérica da ação, o que poderia distorcer os resultados relativos à interpretação conceptual de numerosidade pelas crianças. Nesse sentido, optou-se por dar continuidade ao estudo contrastando as formas verbais no pretérito perfeito do indicativo (ex.: comeu/comeram), cujos resultados são reportados no presente artigo.

Foram selecionados doze verbos para compor os estímulos-teste: seis formando uma estrutura do tipo $\mathrm{V}+\mathrm{NP}$ (ex.: comer doce; pular corda), que constitui uma unidade semântica da ação em que cada personagem aparece com um objeto, e seis estruturas compostas por V+DP (ex.: beijar o cachorro; molhar a flor), que favorece uma interpretação mais referencial da imagem, já que, nas ilustrações desse tipo de estrutura, as duas personagens agem sobre o mesmo objeto (cf. as figuras 2 e 3 a seguir).

Procedimento: $\mathrm{O}$ experimento foi desenvolvido com uma fase de familiarização, uma fase de pré-teste e uma fase de teste. Na familiarização, quatro personagens eram apresentadas como membros de uma família, conforme ilustrado na figura 1:

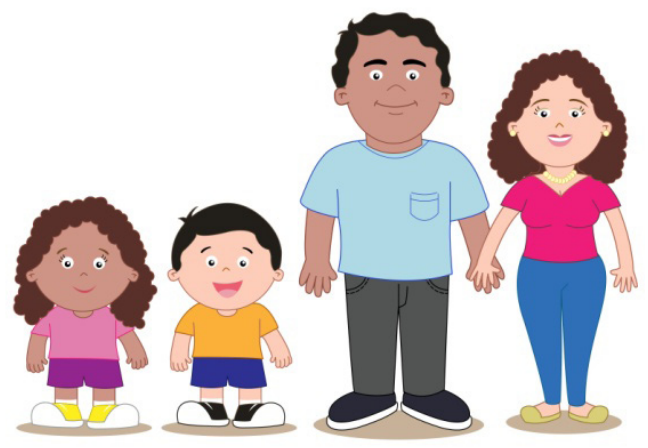

Figura 1: Estímulo visual- fase de familiarização. 
A tarefa foi desenvolvida em formato de jogo, no qual a criança precisava passar por três fases distintas. Em cada fase, havia um conjunto de imagens, e a criança ouvia uma sentença. O participante deveria ouvir a sentença e escolher entre duas imagens a que melhor representa aquilo que foi dito. Após a familiarização, três trials foram inseridos como pré-teste para apresentar a tarefa para a criança, deixá-la habituada com o objetivo e certificar que a criança estava familiarizada com as personagens apresentadas. Se o participante demonstrasse boa compreensão da tarefa durante o pré-teste, passava-se à fase de teste. Exemplos do material visual utilizado são reproduzidos pelas figuras 2 e 3 :
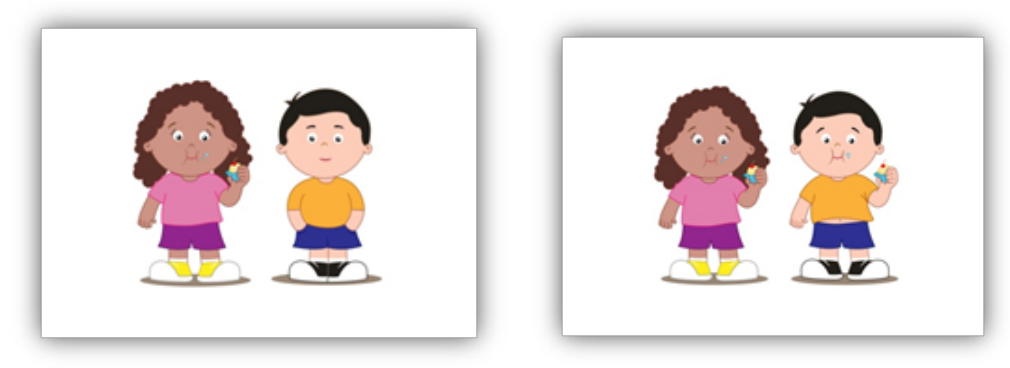

Figura 2: Exemplo de estímulo visual com estímulo linguistico do tipo V+NP (ex.: A(s) criança(s) come-u(-ram) doce / Come-u(-ram) doce).
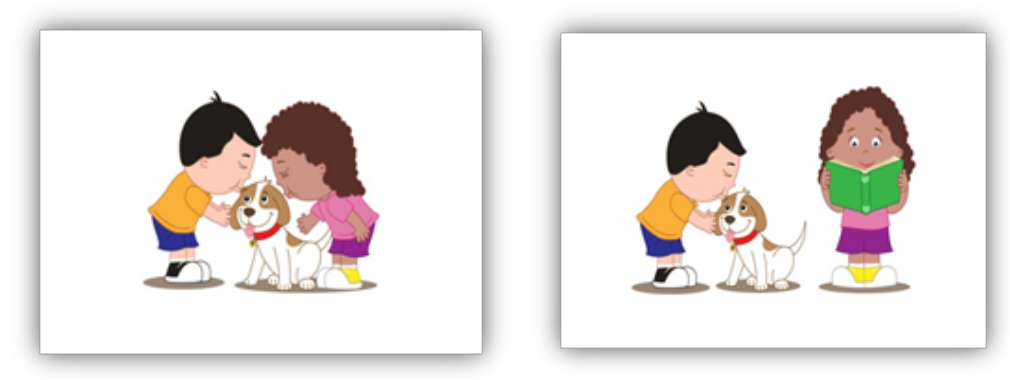

Figura 3: Exemplo de estímulo visual com estímulo linguístico do tipo V+DP (ex.: A(s) criança(s) beij-ou(-aram) o cachorro / Beij-ou(-aram) o cachorro).

A apresentação dos estímulos foi aleatorizada, bem como o lado (esquerda/direita) em que apareceria a imagem-alvo. As respostas dos 
participantes foram anotadas em fichas individuais para posterior análise. A atividade foi aplicada em cinco creches/escolas infantis da cidade de Juiz de Fora/MG, mediante a autorização prévia da direção das instituições e assinatura do Termo de Consentimento Livre e Esclarecido.

\subsection{Resultados e discussão}

Em primeiro lugar, os resultados (número de respostas-alvo) foram submetidos a uma análise de variância ANOVA com design fatorial 2 (grupo socioeconômico) X 2 (faixa etária) X 2 (sujeito) X 2 (número) de modo a poder observar as eventuais interações entre todas as variáveis manipuladas. Obtivemos efeito principal de faixa etária $(\mathrm{F}(1,147)=$ $14.32, p=.000$ ), com médias de respostas-alvo significativamente maiores para o grupo com idade de seis anos.

Gráfico 1: Médias de respostas-alvo (Max. score=3) em função da variável faixa etária.

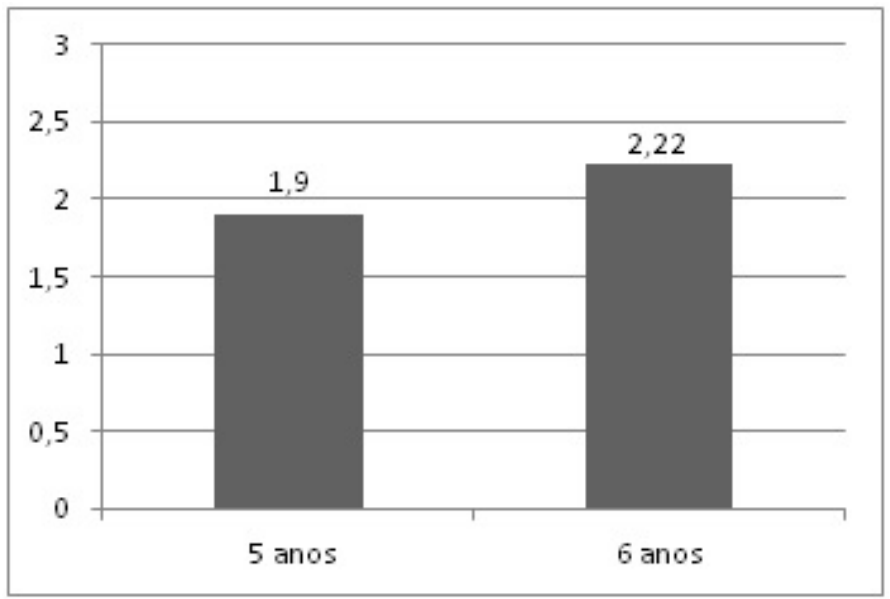

Tal resultado vai ao encontro dos estudos realizados em outras línguas, que indicam uma melhora no desempenho em tarefas de compreensão em função da idade.

Foi obtido, ainda, um efeito principal de grupo socioeconômico $(\mathrm{F}(1,147)=5.820, p=.017)$, com médias significativamente maiores no grupo de crianças que frequentam escola privada. 
Gráfico 2: Médias de respostas-alvo ( $(c=3)$ em função do grupo socioeconômico.

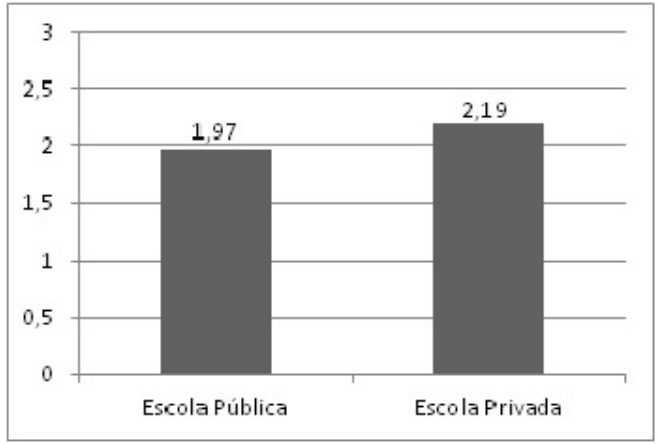

Partindo do pressuposto de que as crianças que frequentam escolas públicas e privadas são expostas a variedades potencialmente distintas da língua, as crianças da escola pública estariam menos expostas à marcação morfofonológica redundante de número, o que poderia explicar a diferença de desempenho entre os dois grupos na tarefa.

A análise também revelou um efeito principal de número $(\mathrm{F}(1,147)$ $=318.2, p=.000$ ), com médias de respostas-alvo significativamente maiores para as condições de plural.

Gráfico 3: Médias de respostas-alvo (Max. score $=3)$ em função da variável número.

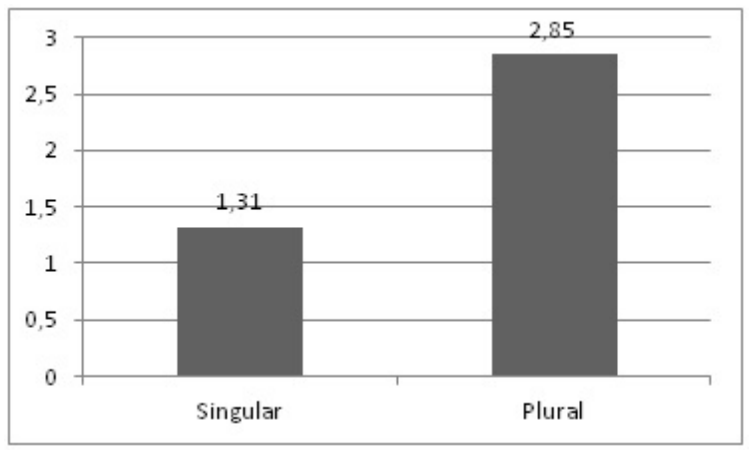

As respostas-alvo nas condições de plural foram mais sistemáticas do que nas condições de singular, sugerindo uma possível leitura genérica para os enunciados no singular, mesmo quando os verbos são apresentados no pretérito perfeito do indicativo. Destacamos que, nas condições de plural, há uma sistematicidade de escolhas pela imagem-alvo não ob- 
servada para o singular, cujos resultados ficaram próximos do nível da chance, o que parece sugerir a percepção e a compreensão da marcação morfofonológica de plural, que seria tomada como informação robusta para a escolha por imagens com "mais de um sujeito" praticando a ação verbal. Os verbos no singular, por sua vez, não são associados de forma sistemática a imagens contendo referentes singulares pelas crianças testadas. Embora uma possível leitura genérica não possa ser excluída sem a aplicação de novos experimentos, o fato de que no PB verbos com morfologia singular não se relacionam de forma categórica a sujeitos singulares, é um fator que pode ter afetado o desempenho das crianças.

Houve, ainda, efeito principal de realização do sujeito $(\mathrm{F}(1,147)$ $=22.04, p=.001$ ), com médias significativamente maiores para as condições de sujeito preenchido. Esse resultado é compatível com a hipótese segundo a qual a marcação explícita tanto no verbo quanto no sujeito da sentença pode facilitar a compreensão das informações relativas à numerosidade. $\mathrm{O}$ fato de o sujeito nulo ser cada vez menos frequente no input a que as crianças estão expostas no PB é outro fator que pode ser relacionado a esse resultado.

Gráfico 4: Médias de respostas-alvo $($ Max. score $=3)$ em função da variável realização do sujeito.

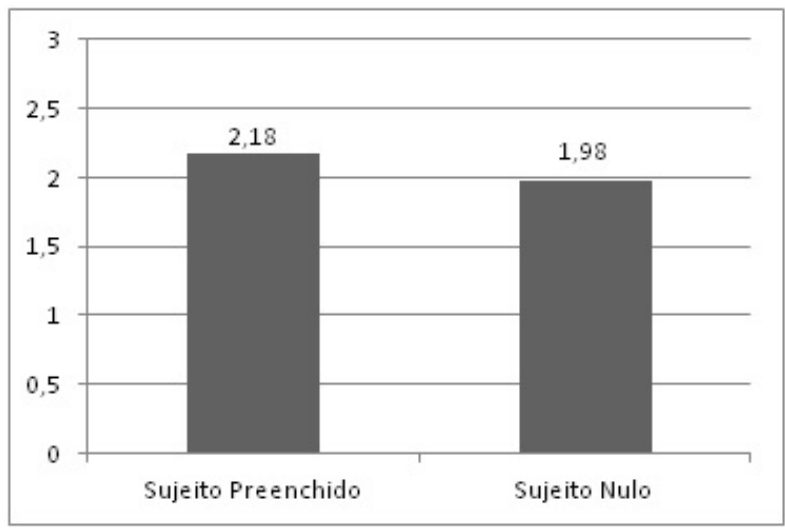

Um efeito de interação entre realização do sujeito $\mathrm{X}$ número $(\mathrm{F}(1,147)=10.81, p=.001)$ também foi registrado, com médias maiores para a condição sujeito preenchido plural. 
Gráfico 5: Médias de respostas-alvo $($ Max. score $=3)$ em função das variáveis realização do sujeito e número.

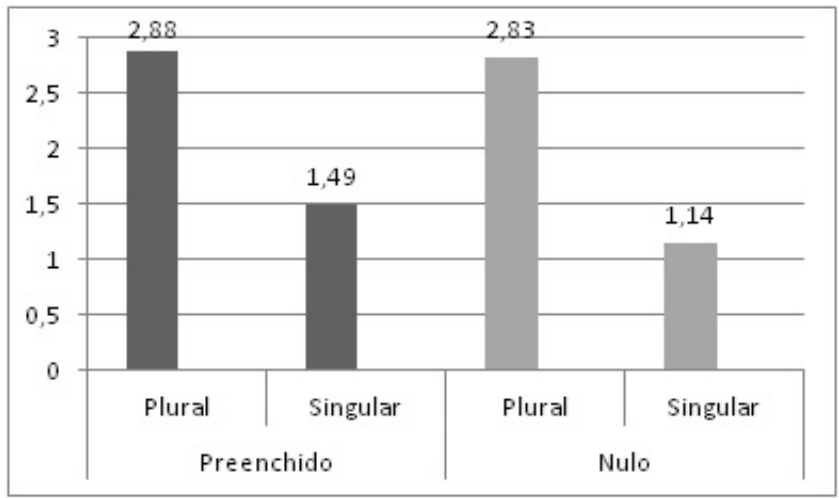

O menor número de respostas-alvo foi registrado na condição sujeito nulo e verbo singular. Já o sujeito preenchido plural concentrou o maior número de respostas-alvo. Tanto no plural quanto no singular, o preenchimento do sujeito parece auxiliar a interpretação do enunciado, apesar de que, na condição plural, a marcação apenas no verbo se revelou uma informação robusta para o mapeamento do enunciado com a imagem-alvo.

Como parte das análises estatísticas, foram conduzidos também testes não paramétricos nos grupos socioeconômicos de cada faixa etária separadamente. Tanto no grupo de 5 quanto no de 6 anos de idade, em ambos os grupos socioeconômicos, houve diferenças estatisticamente significativas na comparação entre as condições experimentais a partir do teste de Friedman: $\chi 2(32)=58.981, p=.001$ ( 5 anos, escola pública), $\chi 2(32)=76.444, p=.001$ (5 anos, escola privada), $\chi 2(40)=68.990, p=.001$ ( 6 anos, escola pública) e $\chi 2(44)=76.445, p=.001$ ( 6 anos, escola privada). Uma análise post hoc por meio do teste de Wilcoxon revelou diferenças estatisticamente significativas, nas duas faixas etárias, na comparação de pares de condições que diferem quanto a número $(p=.000)$ tanto nos grupos de crianças que frequentam escola pública quanto nos grupos que frequentam escola privada. Nos grupos de 5 anos (escola pública e escola privada), a realização do sujeito não se mostra estatisticamente significativa. Já nos grupos de 6 anos, houve resultado estatisticamente significativo apenas na comparação entre as condições sujeito nulo singular X sujeito preenchido singular no grupo de escola privada $(Z=-3.189 \mathrm{~b}$, 
$p=.001$ ), com média maior para a condição de preenchimento do sujeito.

Em conjunto, os resultados obtidos são compatíveis com a ideia de que há diferenças na compreensão da informação de número veiculada pelo morfema verbal em função da idade e do grupo socioeconômico dos participantes. A informação de plural parece ser interpretada de forma consistente, independentemente das variáveis consideradas, enquanto a interpretação da informação de singular não se revelou sistemática no experimento conduzido. A presença de sujeito lexical também se mostrou um fator importante na compreensão das sentenças: sujeitos preenchidos parecem facilitar a identificação dos referentes singulares e plurais.

\section{Considerações finais}

Neste artigo, buscamos discutir o papel do input variável na aquisição da marcação morfofonológica de $3^{\mathrm{a}}$ pessoa do plural em verbos no $\mathrm{PB}$. Em comparação com o estudo desenvolvido por Pérez-Leroux (2005) em espanhol - língua em que a marcação morfofonológica de número no verbo é semelhante ao português, porém consistente - podemos dizer que os resultados encontrados com as crianças brasileiras não divergem dos encontrados com as crianças adquirindo o espanhol. Pelo contrário, considerando que a tarefa desenvolvida neste estudo foi similar à aplicada por PérezLeroux (2005), os resultados encontrados por nosso estudo nas condições de plural sugerem melhor desempenho na compreensão de numerosidade, tanto nas condições de sujeito preenchido quanto nas sentenças de sujeito nulo. Dessa forma, os resultados obtidos até o momento sugerem que, nas faixas etárias testadas (cinco e seis anos), a variação no input recebido pelas crianças não interfere na realização da tarefa, sendo os resultados compatíveis aos encontrados em línguas nas quais a marcação morfofonológica é categórica. A diferença, no entanto, no desempenho dos grupos de 5 e de 6 anos de idade, bem como os resultados estatisticamente significativos na comparação entre dois grupos socioeconômicos distintos são pontos a serem melhor explorados nos futuros desdobramentos da pesquisa.

A interpretação atribuída a enunciados com sujeitos nulos ou preenchidos e verbos singulares é outro ponto que merece destaque. Essa questão resulta particularmente relevante para uma melhor compreensão do processo de aquisição não só da morfologia verbal, mas também no que diz respeito ao processo de identificação - por parte da criança - de relações entre constituintes sintáticos (ex.: relações de concordância entre sujeito e verbo). As crianças avaliadas neste estudo registraram médias 
de respostas-alvo maiores nas condições de sujeito preenchido. Em que medida, para a criança adquirindo o PB, o sujeito da sentença constitui o locus relevante para a identificação e interpretação da informação relativa a número, é um ponto a ser aprofundado.

\section{NOW IT IS, NOW IT IS NOT: VARIABLE INPUT AND $3^{\text {RD }}$ PERSON PLURAL VERBAL INFLECTION ACQUISITION IN BRAZILIAN PORTUGUESE}

\section{ABSTRACT}

We investigate the perception of the $3^{\text {rd }}$ person plural verbal inflection and the comprehension of the concept of plurality of this morpheme by children acquiring Brazilian Portuguese (BP). $\mathrm{BP}$ exhibits variable number agreement on nominal and verbal phrases. Previous studies in several languages point out that, although children produce number inflection by the age of three, they have difficulty on comprehension tasks until the age of six (JOHNSON; DE VILLIERS; SEYMOR, 2005; PÉREZ-LEROUX, 2005; LEGENDRE et al., 2010; BLÁHOVÁ; SMOLIK, 2014). On our study, an experimental task, developed with the Picture Identification Task technique, aimed at verifying if, despite the variable nature of the number agreement in BP, six and five-year-old children identify the verbal form of the $3^{\text {rd }}$ person plural in sentences of null subject (Comeram doce) and associate this form to an action practiced by more than one entity and if the singular verbal form is associated with the concept of singularity (Cотеи doce). Sentences with number information on the subject and the verb were also tested (As crianças comeram doce vs. A criança comeu doce). Our results suggest that plural pictures were systematically chosen for plural linguistic stimuli, although there was a preference for plural pictures also with singular sentences. The variable input seems not to interfere on the perception and comprehension of the plural verbal morpheme on the age tested in our study.

KEYWORDS: verbal acquisition; variation, variable verbal inflection; perception; comprehension 


\section{NOTAS}

${ }^{1} \mathrm{O}$ presente artigo é resultado de uma pesquisa conduzida no âmbito do projeto Interfaces internas e externas na aquisição e no processamento adulto de L1 e L2: concordância e tópico/foco no PB, financiado pela FAPEMIG (Edital 1/2015 Demanda Universal - Processo APQ-00988-15). O referido projeto conta com a aprovação do Comitê de Ética da Universidade Federal de Juiz de Fora/UFJF (CAAE: 44123015.6.0000.5147).

${ }^{2}$ Exemplos retirados do corpus de Molina (em prep.).

\section{REFERÊNCIAS}

ALVES, M. T. G.; SOARES, J. F.; XAVIER, F. P. Índice Socioeconômico das Escolas de Educação Básica Brasileiras. Ensaio: aval. pol. públ. Educ., Rio de Janeiro, v.22, n. 84, p. 671-704, jul./set. 2014.

AVELAR, J. Gramática, competição e padrões de variação: casos com ter/haver e de/em no português brasileiro. Rev. Est. Ling., Belo Horizonte, v. 14, n. 2, p. 99-143, jun./dez. 2006.

BLÁHOVÁ, V.; SMOLIK, F. Early Comprehension of Verb Number Morphemes in Czech: Evidence for a Pragmatic Account. BUCLD 38 Proceedings, 2014. Disponível em: http://www.academia.edu/11817242/Early_Comprehension_of_ Verb_Number_Morphemes_in_Czech_Evidence_for_a_Pragmatic_Account CASTRO, A.; FERRARI-NETO, J. Um estudo contrastivo do PE e do PB com relação à identificação de informação de número no DP. Letras de Hoje. Porto Alegre, v. 42, n. 1, p. 65-76, março, 2007.

CHOMSKY, N. Lectures on government and binding. Dordrecht: Foris, 1981. Knowledge of language. New York: Praeger, 1986.

CORRÊA, L. M. S.; NAME, M. C. L.; FERRARI-NETO, J. O processamento de informação de interface na aquisição de gênero e de número no português brasileiro. Letras de Hoje, 39(3):123-37, 2004.

COSTA, J.; FIGUEIREDO SILVA, M. C. Notes on nominal e verbal agreement in Portuguese. Rivista di Grammatica Generativa, Padova, v. 27, 17-29, 2002.

DUARTE, M. E. L. Do pronome nulo ao pronome pleno: a trajetória do sujeito no português do Brasil. In: ROBERTS, I.; KATO, M. A. (Orgs.) Português Brasileiro: uma viagem diacrônica. 2.ed. Campinas, SP: Editora UNICAMP, 1996.

FERRARI-NETO, J. Reconhecimento do número gramatical e processamento 
da concordância de número no sintagma determinante na aquisição do português brasileiro. 112f. Dissertação (Mestrado). Departamento de Letras. Rio de Janeiro: PUC-Rio, 2003.

Aquisição de número gramatical no português brasileiro: processamento de informação de interface e concordância. 154f. Tese (Doutorado). Departamento de Letras. Rio de Janeiro: PUC-Rio, 2008.

FIGUEIRA, R. A. A aquisição do paradigma verbal do português: as múltiplas direções dos erros. In: ALBANO, E.; COUDRY, M. I. H.; POSSENTI, S.; ALKMIM, T. (Orgs). Saudades da língua: a linguística e os 25 anos do Instituto de Estudos da Linguagem da UNICAMP. Campinas, SP: Mercado de Letras, 2003.

GALVES, C. C. O enfraquecimento da concordância no português brasileiro. In: ROBERTS, I.; KATO, M. A. (Orgs.) Português Brasileiro: uma viagem diacrônica. 2.ed. Campinas, SP: Editora UNICAMP, 1996.

GOMES, C. A.; PONTES, M. C. V; ALMEIDA, M. C. S.; ABREU, A. C. B. de. Variação e aquisição da flexão nominal e da flexão verbal. Revista Gragoatá. Niterói, n. 30, p. 39-54, 1. sem. 2011.

JOHNSON, V. E.; DE VILLIERS, J. G.; SEYMOR, H. N. Agreement without understanding? The case of third person singular/s/. First Language, v. 25 (3), 317-330, 2005.

KATO, M. A gramática do letrado: questões para a teoria gramatical. MARQUES, $M$. et al. (Orgs). Ciências da Linguagem: trinta anos de investigação e ensino. Braga: CEHUM (U. do Minho), p. 131-145, 2005.

LEGENDRE, G.; BARRIERE, I.; GOYET, L.; NAZZI, T. Comprehension of Infrequent Subject-Verb Agreement Forms: Evidence From French-Learning Children. Child Development, v. 81, n. 6, p. 1859-1875, 2010.

LEMLE, M.; NARO, A. J. Competências básicas do português. Relatório final de pesquisa apresentado às instituições patrocinadoras Fundação Movimento Brasileiro (MOBRAL) e Fundação Ford. Rio de Janeiro, 1977.

LESSA-DE-OLIVEIRA, A. S. C. Aquisição da linguagem e variação linguística. Estudos Linguísticos XXXIV, p. 409-414, 2005.

LIGHTFOOT, D. Language acquisition and language change. WIREs Cognitive Science, 1: 677-684, 2010.

LOPES, R. E. V.; SOUZA, T. T.; ZILLI, A. S. Tempo e concordância e seus efeitos na aquisição do português brasileiro. In: 6o. Encontro do CELSUL, 2004, Florianópolis. Anais do 6o. Encontro do CELSUL, p. 1-10, 2005.

MILLER, K.; SCHMITT, C. Variable vs. Consistent Input: Comprehension of Plural Morphology and Verbal Agreement in Children. In: BRUCART, J. M.; 
GAVARRÓ, A.; SOLÀ, J. Merging Features: Computation, Interpretation and Acquisition. New York: Oxford University Press, 2009.

Variable Input and the Acquisition of Plural Morphology. Language Acquisition, 19:3, 223-261, 2012.

MOLINA, D. S. L. A aquisição verbal e o processamento morfológico por crianças adquirindo o PB. 165f. Dissertação (mestrado acadêmico) - Universidade Federal de Juiz de Fora, Faculdade de Letras. Programa de Pós-Graduação em Linguística, 2014.

Aquisição da linguagem e variação linguística: um estudo sobre a flexão verbal variável na aquisição do PB. Tese de doutorado: UFJF, em prep.

NAME, C.; MOLINA, D. S. L. Aquisição verbal e processamento morfológico: um estudo preliminar. Fórum Linguístico, Florianópolis, v. 11, n. 3, p. 293-307, jul./set. 2014.

NARO, A. J. The Social and the Structural Dimensions of a Syntatic Change. Language, n. 57, p. 63-98, 1981.

NARO, A. J.; SCHERRE, M. M. P (org.). Origens do Português Brasileiro. São Paulo: Parábola Editorial, 2007.

PÉREZ-LEROUX, A. T. Number problems in children. Proceedings of the 2005 annual conference of the Canadian Linguistics Association, 1-12, 2005. Disponível em: http://westernlinguistics.ca/Publications/CLA-ACL/Perez-Leroux.pdf.

SCHERRE, M. M. P.; NARO, A. J. Sobre a concordância de número no português falado no Brasil. In: RUFFINO, G. (Org.) Dialettologia, geolinguistica, sociolinguistica (Atti del XXI Congresso Internazionale di Linguistica e Filologia Romanza) Centro di Studio Filologici e Linguistici Siciliani, Universitá di Palermo. Tübingen: Max Niemeyer Verlag, 5:509-523, 1998.

- Mudança sem mudança: a concordância de número no português brasileiro. SCRIPTA, Belo Horizonte, v. 9, n. 18, 107-129, 2006.

YANG, C. Knowledge and learning in natural language. New York: Oxford University Press, 2002.

Recebido em: 28/04/2017

Aceito em: 07/07/2017 